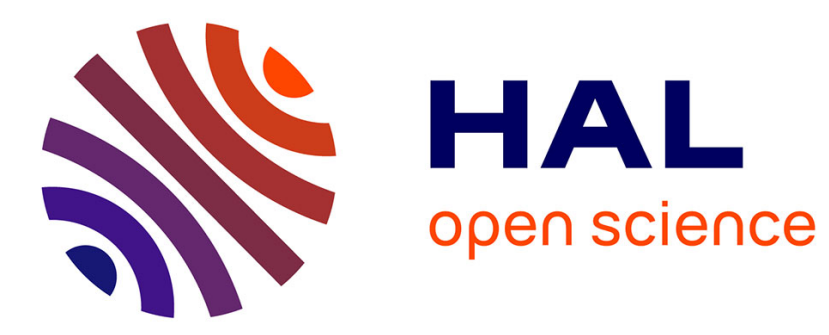

\title{
Line competition in an intracavity diode-pumped Yb:KYW laser operating at $981 \mathrm{~nm}$
}

François Balembois, Marc Castaing, Patrick Georges, Georges Thierry

\section{To cite this version:}

François Balembois, Marc Castaing, Patrick Georges, Georges Thierry. Line competition in an intracavity diode-pumped Yb:KYW laser operating at $981 \mathrm{~nm}$. Journal of the Optical Society of America B, 2011, 28 (1), pp.115-122. hal-00671570

\section{HAL Id: hal-00671570 \\ https://hal-iogs.archives-ouvertes.fr/hal-00671570}

Submitted on 30 Mar 2012

HAL is a multi-disciplinary open access archive for the deposit and dissemination of scientific research documents, whether they are published or not. The documents may come from teaching and research institutions in France or abroad, or from public or private research centers.
L'archive ouverte pluridisciplinaire HAL, est destinée au dépôt et à la diffusion de documents scientifiques de niveau recherche, publiés ou non, émanant des établissements d'enseignement et de recherche français ou étrangers, des laboratoires publics ou privés. 


\title{
Line competition in an intracavity diode-pumped Yb:KYW laser operating at $981 \mathrm{~nm}$
}

\author{
François Balembois, ${ }^{1, *}$ Marc Castaing, ${ }^{1,2}$ Patrick Georges, ${ }^{1}$ and Thierry Georges ${ }^{2}$ \\ ${ }^{1}$ Laboratoire Charles Fabry de l'Institut d'Optique, CNRS, Université Paris-Sud, \\ Campus Polytechnique, RD128, 91127 Palaiseau Cedex, France \\ ${ }^{2}$ Oxxius SA, 4 Rue Louis de Broglie, F-22300 Lannion, France \\ *Corresponding author: francois.balembois@institutoptique.fr
}

Received September 9, 2010; revised October 22, 2010; accepted October 25, 2010; posted November 4, 2010 (Doc. ID 134771); published December 17, 2010

\begin{abstract}
This paper proposes an analysis of a Yb:KYW laser emitting at $981 \mathrm{~nm}$ intracavity pumped by a $\mathrm{Nd}^{2} \mathrm{YVO}_{4}$ laser operating at $914 \mathrm{~nm}$. It gives some guidelines to optimize the laser performance. An output power of $1 \mathrm{~W}$ has been obtained at $981 \mathrm{~nm}$ for a pump power of $23 \mathrm{~W}$ at $808 \mathrm{~nm}$. It presents a simple and original model to deal with the line competition between $981 \mathrm{~nm}$ and the other lines at 1000 and $1023 \mathrm{~nm}$ and explains how a temperature increase can promote the $981 \mathrm{~nm}$ laser emission. This approach could be useful for other lasers that are subject to line competition. (C) 2010 Optical Society of America

OCIS codes: $\quad 140.3480,140.3580,140.3430,140.3615,140.3530$.
\end{abstract}

\section{INTRODUCTION}

Laser source developments around $980 \mathrm{~nm}$ based on ytterbium-doped materials are rising due to their wide range of applications. Moreover, the possibility of second harmonic generation (SHG) for a blue emission around $488 \mathrm{~nm}$ (corresponding to an argon-ionized transition) is another motivation for increasing the performance of this kind of source. Still, the three-level nature of the transition involves the use of very high pump intensity in order to avoid reabsorption losses at the lasing wavelength. This explains why the first laser systems emerging at $980 \mathrm{~nm}$ were fiber lasers [1,2], now demonstrating impressive output powers [3,4]. Indeed, the pump is confined throughout the propagation, enabling it to maintain a high level of population inversion and to limit the reabsorption losses. Moreover, the pump-signal overlap is enhanced in comparison with a direct diode pumping. However, this architecture suffers from two intrinsic limitations. First, the compacity is limited by the fiber length and its minimum radius of curvature. Second, cw intracavity SHG remains difficult to achieve with this kind of setup since the intracavity power is generally low in fiber lasers. Consequently, SHG with fiber lasers is generally carried out in an extracavity configuration. This leads to low efficiency and requires the use of very efficient nonlinear crystals (like ppLN or ppKTP) together with a high power at the fundamental wavelength $980 \mathrm{~nm}[\underline{5}, \underline{6}]$.

On the opposite hand, Yb-doped bulk crystals could be an alternative since they would offer the possibility of intracavity SHG and microchip integration. However, the direct diode pumping of crystalline three-level laser media remains difficult due to the bad spatial beam quality of high-power laser diodes. The intracavity pumping configuration represents one way to solve this problem as demonstrated in a Yb:S-FAP crystal [7]. Nevertheless, two problems appear with Yb:S-FAP. First, the emission wavelength is slightly red shifted with respect to the $976 \mathrm{~nm}$ operation required to approach the argon laser line after SHG. Moreover, this crystal is not commercially available. Closer to the required wavelength and more widely used are the ytterbium-doped tungstate crystals family, such as $\mathrm{Yb}: \mathrm{KY}\left(\mathrm{WO}_{4}\right)_{2}(\mathrm{Yb}: \mathrm{KYW})$ or $\mathrm{Yb}: \mathrm{KGd}\left(\mathrm{WO}_{4}\right)_{2}$ $(\mathrm{Yb}: \mathrm{KGW}$ ). These crystals exhibit a strong emission line at $981 \mathrm{~nm}$. Previously demonstrated under Ti:sapphire pumping [8], the first laser emission with $\mathrm{Yb}: \mathrm{KYW}$ at $981 \mathrm{~nm}$ was achieved in 2009 [9] with an intracavity pumping configuration. A similar experiment was carried out later [10] demonstrating around $100 \mathrm{~mW}$ at $490.5 \mathrm{~nm}$ by SHG.

Through these publications, it appears that the laser design is not obvious. Indeed, the emission spectrum of Yb-doped tungstate is continuous between 981 and $1040 \mathrm{~nm}$ with peaks at 981 , 1000,1023 , and $1040 \mathrm{~nm}$ [11], following the crystal orientation. As opposed to $\mathrm{Yb}: \mathrm{S}-\mathrm{FAP}$ [12], strong gain competition will occur between the $981 \mathrm{~nm}$ line and the other transitions. Moreover, the design of an intracavity-pumped laser requires adjusting the absorption carefully: if the absorption at the pump wavelength is too high, the threshold of the pump laser will increase, reducing the efficiency of the pump laser. Conversely if the absorption is too low, the output at $981 \mathrm{~nm}$ will be reduced.

The purpose of this paper is to give a theoretical analysis in order to design a Yb:tungstate laser at $981 \mathrm{~nm}$ with intracavity pumping at $914 \mathrm{~nm}$ by a $\mathrm{Nd}: \mathrm{YVO}_{4}$ laser. We also explain how to manage the line competition. This work is based on experimental results reported in [9] and a theoretical approach based on gain calculations. In Section 2, we explain how to choose the tungstate crystal: $\mathrm{Yb}: \mathrm{KYW}$ or $\mathrm{Yb}: \mathrm{KGW}$. Section 3 deals with the absorption of the tungstate crystal, taking the intracavity pumping scheme into account. Section $\underline{4}$ explains how to adjust the transmission of the mirrors to avoid the line competition and promote laser emission at $981 \mathrm{~nm}$. Finally, we investigate the temperature effect on the line competition between the 981 and $1000 \mathrm{~nm}$ transitions.

\section{CHOICE OF THE Yb-DOPED TUNGSTATE CRYSTAL}

The most widely used and commercially available tungstate crystals are $\mathrm{Yb}: \mathrm{KGW}$ and $\mathrm{Yb}: \mathrm{KYW}$. Their properties are 
relatively similar [13-15], and it is difficult to know which is the best for a laser emission at $981 \mathrm{~nm}$. Table 1 gives the main properties to be considered for laser operation at $981 \mathrm{~nm}$. The cross sections are from $[\underline{13}, \underline{14}]$ and the lifetimes are from [15]. One should note that different values are given for the lifetimes : from 300 [16] to $600 \mu \mathrm{s}$ [17].

The effective emission cross section is higher for $\mathrm{Yb}: \mathrm{KGW}$, whereas the effective absorption cross sections and the lifetimes are similar. One would thus be inclined to choose $\mathrm{Yb}: \mathrm{KGW}$ over $\mathrm{Yb}: \mathrm{KYW}$. However, one has to take the line competition into account between $981 \mathrm{~nm}$ and the closest peak after $981 \mathrm{~nm}$ corresponding to $1000 \mathrm{~nm}$ for $\mathrm{Yb}: \mathrm{KYW}$ and $997 \mathrm{~nm}$ for $\mathrm{Yb}$ :KGW (Fig. 1).

To investigate this problem, we consider the gain cross section $\sigma_{g}$ :

$$
\sigma_{g}=\left(\sigma_{\mathrm{el}}+\sigma_{\mathrm{al}}\right) \cdot x-\sigma_{\mathrm{al}},
$$

where $\sigma_{\mathrm{el}}$ and $\sigma_{\mathrm{al}}$ are the effective emission cross section and the effective absorption cross section at the considered laser wavelength, $x$ is the ratio of the upper-level population density $n_{2}$ to the total density of $\mathrm{Yb}$ ions $n_{t}: x=n_{2} / n_{t}$. To reach the transparency at $981 \mathrm{~nm}$ (meaning a gain coefficient equal to zero), $x$ needs to be 0.44 for $\mathrm{Yb}$ :KGW and 0.46 for $\mathrm{Yb}$ :KYW. This value is denoted $x_{\mathrm{tr}}$. For this population inversion ratio, we calculate the gain cross section at $1000 \mathrm{~nm}$ in Yb:KYW and $997 \mathrm{~nm}$ for Yb:KGW. The results reported in Table 2 clearly show that the gain at $997 \mathrm{~nm}$ is much higher for $\mathrm{Yb}: \mathrm{KGW}$ than for $\mathrm{Yb}: \mathrm{KYW}$ at $1000 \mathrm{~nm}$. Consequently, to limit the line competition, we prefer $\mathrm{Yb}: \mathrm{KYW}$, even if its spectroscopic properties are slightly lower at $981 \mathrm{~nm}$.

\section{CHOICE OF THE Yb:KYW ABSORPTION}

The basic principle for the intracavity pumping of $\mathrm{Yb}: \mathrm{KYW}$ is reported in Fig. 2. For the pumping, we chose a $\mathrm{Nd}: \mathrm{YVO}_{4}$ laser pumped by a laser diode at $808 \mathrm{~nm}$. This laser operated at $914 \mathrm{~nm}$ is referred to as the pump laser in the rest of the paper. $914 \mathrm{~nm}$ is far from the absorption band of $\mathrm{Yb}: \mathrm{KYW}$, which is typically between 930 and $981 \mathrm{~nm}$. However, the small absorption coefficient will be compensated by the high value of the intracavity power at $914 \mathrm{~nm}$. The $\mathrm{Yb}: \mathrm{KYW}$ crystal is intro-
Table 1. Comparison of the Spectroscopic Properties at 981 nm for Yb:KGW and Yb:KYW

\begin{tabular}{lcc}
\hline & Yb:KYW & Yb:KGW \\
\hline Effective emission & $13.4 \times 10^{-20} \mathrm{~cm}^{2}$ & $15 \times 10^{-20} \mathrm{~cm}^{2}$ \\
cross section $\sigma_{\mathrm{el}}(981 \mathrm{~nm})$ & & \\
Effective absorption & $11.5 \times 10^{-20} \mathrm{~cm}^{2}$ & $11.6 \times 10^{-20} \mathrm{~cm}^{2}$ \\
$\quad$ cross section $\sigma_{\mathrm{al}}(981 \mathrm{~nm})$ & & \\
Lifetime $\tau$ & $440 \mu \mathrm{s}$ & $438 \mu \mathrm{s}$ \\
\hline
\end{tabular}

duced in the cavity of the $914 \mathrm{~nm}$ laser, which is a high-finesse resonator. For the sake of simplicity, the cavities at 981 and $914 \mathrm{~nm}$ are superimposed, thanks to specific coatings on the mirrors.

In an intracavity pumping configuration, the choice of the crystal absorption is critical: if it is too high, it increases the threshold of the pump laser; if it is too low, it reduces the output power. Indeed, the optimum absorption is strongly related to the optimum output coupling for the pump laser as previously mentioned for intracavity pumped lasers [18]. To specify the Yb:KYW crystal (i.e., length and doping concentration), one has to study the pump laser first. The experimental setup for the pump $\mathrm{Nd}: \mathrm{YVO}_{4}$ laser is presented in Fig. 3 .

We used a laser diode emitting at $808 \mathrm{~nm}$ coupled into a $100 \mu \mathrm{m}$ core diameter fiber with a numerical aperture of 0.22 . This diode provides up to $25 \mathrm{~W}$ of unpolarized emission. The fiber output is imaged with two identical doublets $(60 \mathrm{~mm}$ focal length) into the $\mathrm{Nd}: \mathrm{YVO}_{4}$ crystal with a waist radius of $50 \mu \mathrm{m}$. The $5 \mathrm{~mm}$ long, a-cut $0.1 \%$ doped $\mathrm{Nd}: \mathrm{YVO}_{4}$ crystal is antireflection (AR) coated at 914 and $981 \mathrm{~nm}$ to reduce the intrinsic losses of the cavity. It was oriented with its $c$ axis perpendicular to the plan of the cavity such that laser emission at $914 \mathrm{~nm}$ will be linearly polarized perpendicularly to this plan. It is also AR coated at $1064 \mathrm{~nm}$ to prevent laser oscillation between the two facets of the crystal. The first three mirrors of the cavity $\left(M_{1}, M_{2}\right.$, and $\left.M_{3}\right)$ are highly reflective at both 914 and $981 \mathrm{~nm}$ and highly transmissive at $1064 \mathrm{~nm}$, once again to prevent the parasitic oscillation of the high gain transition line in the $\mathrm{Nd}: \mathrm{YVO}_{4}$. The last mirror of the cavity $\left(M_{4}\right)$ is the output coupler for the $981 \mathrm{~nm}$ emission, but still highly reflecting at $914 \mathrm{~nm}$. Different output couplers are used in this
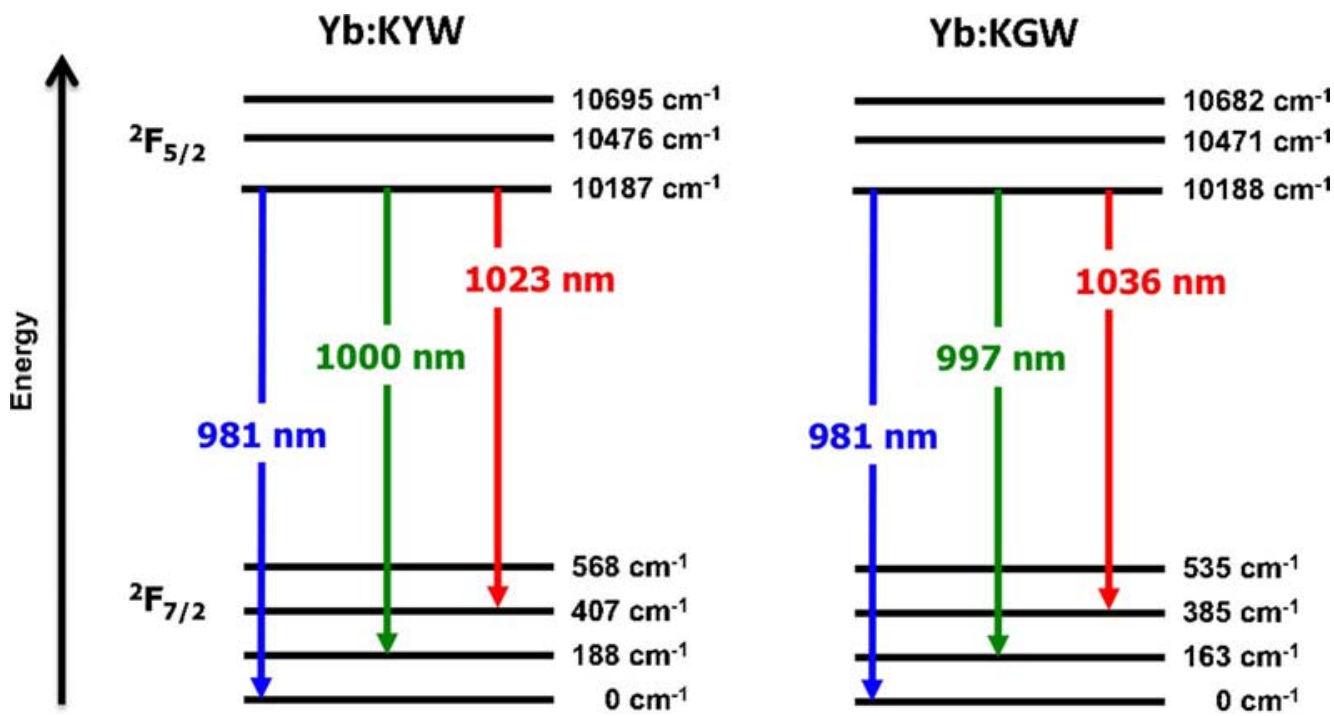

Fig. 1. (Color online) Energy levels in $\mathrm{Yb}: \mathrm{KYW}$ and $\mathrm{Yb}: \mathrm{KGW}$ and associated emission wavelengths. 
Table 2. Comparison of the Gain Cross Section at $1000 \mathrm{~nm}$ and $997 \mathrm{~nm}$ for Yb:KYW and Yb:KGW, Respectively, for a Transparency at $981 \mathrm{~nm}$

\begin{tabular}{lcc}
\hline & Yb:KYW & Yb:KGW \\
\hline$x_{\text {tr }}$ at 981 nm transparency & 0.46 & 0.44 \\
Wavelength considered & $1000 \mathrm{~nm}$ & $997 \mathrm{~nm}$ \\
Effective emission & $5.1 \times 10^{-20} \mathrm{~cm}^{2}$ & $8.3 \times 10^{-20} \mathrm{~cm}^{2}$ \\
$\quad$ cross section $\sigma_{\mathrm{el}}$ & & \\
Effective absorption & $1.6 \times 10^{-20} \mathrm{~cm}^{2}$ & $1.8 \times 10^{-20} \mathrm{~cm}^{2}$ \\
$\quad$ cross section $\sigma_{\mathrm{al}}$ & & \\
$\sigma_{g}\left(x_{\mathrm{tr}}\right)$ (at 1000 or $\left.997 \mathrm{~nm}\right)$ & $1.5 \times 10^{-20} \mathrm{~cm}^{2}$ & $2.6 \times 10^{-20} \mathrm{~cm}^{2}$ \\
\hline
\end{tabular}

${ }^{a}$ The cross sections come from $[\underline{13}, \underline{14}]$.

study with a transmission between $20 \%$ and $70 \%$ at $981 \mathrm{~nm}$. The second waist of the cavity (between $M_{3}$ and $M_{4}$ ), has a size of $40 \mu \mathrm{m}$ (radius) and is used to introduce the AR-coated (at 981 and $914 \mathrm{~nm}$ ) Yb:KYW crystal.

Knowing all the parameters of the laser, we developed a theoretical simulation to find the optimum output coupling at $914 \mathrm{~nm}$ of this laser. For the calculations, we used the formalism described in [19]. Figure 4 gives the computed output power versus the transmission of the output coupler. It shows an optimum coupling around 7\% at $914 \mathrm{~nm}$. Indeed, the absorption of the $\mathrm{Yb}$ :KYW crystal can be considered as a coupling outside the cavity. The crystal absorption is then equivalent to the transmission of an output coupler, and the absorbed power at $914 \mathrm{~nm}$ is equivalent to the output power at $914 \mathrm{~nm}$. For the

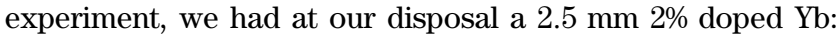
KYW (corresponding to a doping concentration of $1.27 \times$ $10^{20}$ atoms per $\mathrm{cm}^{2}$ ). The crystal was cut along the $\mathrm{Ng}$ axis in order to benefit from the strong emission at $981 \mathrm{~nm}$ for a polarization along the Nm axis. Following the spectral shape of the effective absorption cross section $\sigma_{\text {ap }}$ [13], we can estimate that $\sigma_{\mathrm{ap} / \mathrm{Nm}}(914 \mathrm{~nm})=0.4 \times 10^{-20} \mathrm{~cm}^{2}$ for a polarization parallel to the Nm axis and $\sigma_{\mathrm{ap} / \mathrm{Np}}(914 \mathrm{~nm})=0.2 \times 10^{-20} \mathrm{~cm}^{2}$ for a polarization parallel to the $\mathrm{Np}$ axis. This leads to a double pass absorption of $23.8 \%$ for the Nm axis and $12.2 \%$ for the Np axis, in small signal, i.e., without saturation of absorption. As shown in Fig. 4, the absorption parallel to the $\mathrm{Np}$ axis is relatively close the optimum, whereas the absorption parallel to the Nm axis is too high. As the $\mathrm{Nd}: \mathrm{YVO}_{4}$ laser emits a linearly polarized beam at $914 \mathrm{~nm}$, the crystal must be oriented such that its $\mathrm{Np}$ axis is parallel to the $\mathrm{Nd}: \mathrm{YVO}_{4}$ linear polarization. This was confirmed experimentally: with the Yb:KYW Np axis perpendicular to the $\mathrm{Nd}: \mathrm{YVO}_{4}$ polarization, the laser at $914 \mathrm{~nm}$ was very close to the threshold at the maximum of pump power ( $23 \mathrm{~W}$ at $808 \mathrm{~nm}$ ). For the other orientation ( $\mathrm{Np}$ axis parallel), the pump power at threshold was reduced to less than $8 \mathrm{~W}$.

The absorption of the Yb:KYW may also depend on the laser regime: if the output coupling at $981 \mathrm{~nm}$ is high, the population inversion needs to be significant. It is correlated with a

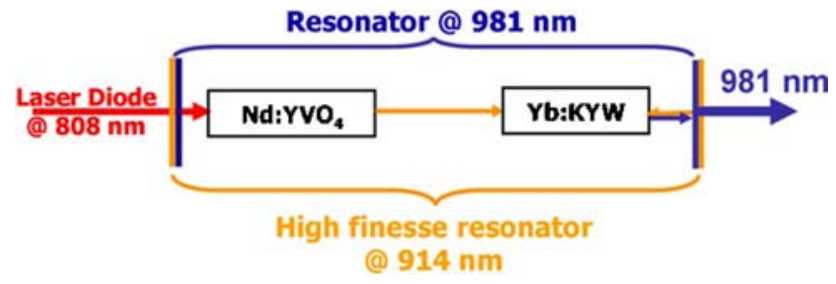

Fig. 2. (Color online) Basic principle for Yb:KYW intracavity pumping.

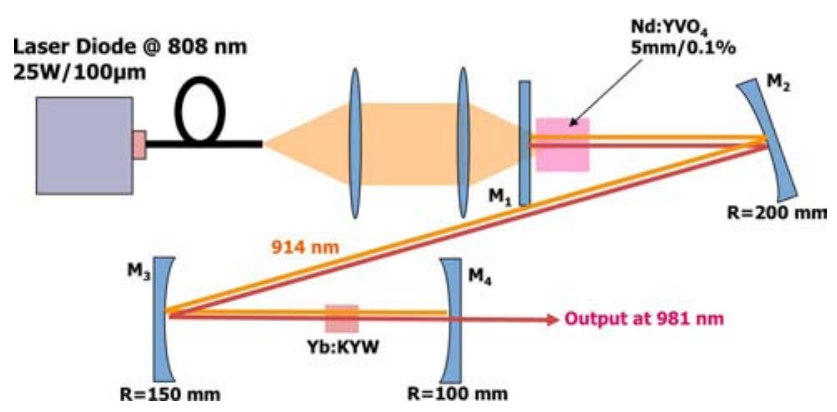

Fig. 3. (Color online) Experimental setup for laser operation at $981 \mathrm{~nm}$ under intracavity pumping. $M_{1}, M_{2}$, and $M_{3}$ are highly reflective mirrors at both 914 and $981 \mathrm{~nm}$ and highly transmissive at $1064 \mathrm{~nm} . M_{1}$, is the output coupler at $981 \mathrm{~nm}$, and it is also highly reflective at $914 \mathrm{~nm}$.

depletion of the ground state and, hence, to a saturation of the absorption at $914 \mathrm{~nm}$. In this case, the small signal absorption is not the relevant parameter to choose the appropriate $\mathrm{Yb}: \mathrm{KYW}$. One has to choose a crystal with a small signal absorption higher than the optimum value given in Fig. 4 . Conversely, if the laser operates in a highly reflective cavity at $981 \mathrm{~nm}$, as it is the case for intracavity SHG, the ground state depletion is limited, and one has to chose a small signal absorption close to the optimum value.

\section{CHOICE OF THE MIRROR TRANSMISSION: EFFECT OF THE LINE COMPETITION}

In this section, we consider the line competition between the $981 \mathrm{~nm}$ line and the closest lines at 1000 and $1023 \mathrm{~nm}$ existing in $\mathrm{Yb}: \mathrm{KYW}$. Even if the emission spectrum is continuous in $\mathrm{Yb}: \mathrm{KYW}$, we consider only the emission at these peak wavelengths where the laser will tend to oscillate predominantly. As shown in Fig. 1, these transitions start from the same emitting level, but the lower level is different. It is the ground state for the transition at $981 \mathrm{~nm}$, and it corresponds to higher energy levels for the transitions at 1000 and $1023 \mathrm{~nm}$.

We focus the study on the oscillation threshold at the different wavelengths as a function of the pump power at $914 \mathrm{~nm}$. In our case of intracavity pumping, the pump power is the intracavity power $P_{914}$ at $914 \mathrm{~nm}$. From the Fig. 4 (by dividing the output power by the transmission), we can estimate that the intracavity power at $914 \mathrm{~nm}$ can reach values on the order of $100 \mathrm{~W}$ at maximum pump power. This order of

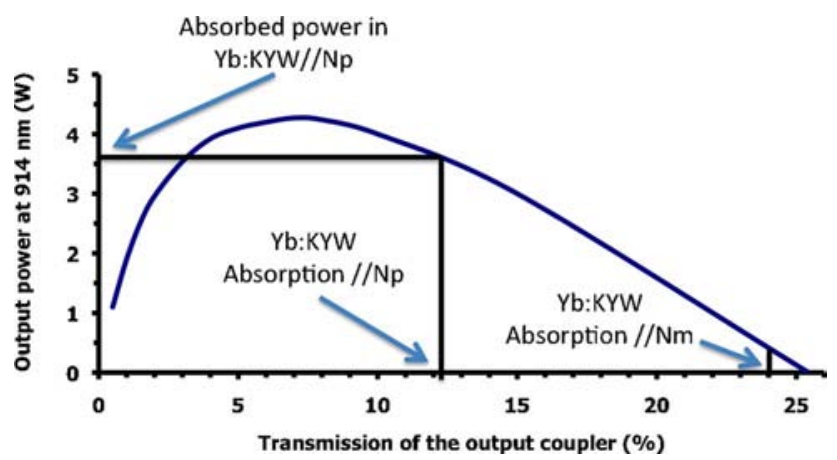

Fig. 4. (Color online) Computed optimum output coupling for the $\mathrm{Nd}: \mathrm{YVO}_{4}$ laser pumped at $23 \mathrm{~W}$. The passive losses are fixed to $3 \%$ at $914 \mathrm{~nm}$ to take the different mirrors into account. The absorptions of our $\mathrm{Yb}: \mathrm{KYW}$ are given in double pass. 
magnitude was also experimentally confirmed by the measurement of the power leaking through the mirror M3.

In order to calculate the small signal gain coefficient, different approximations can be done. The Rayleigh length in the Yb:KYW is approximately $10 \mathrm{~mm}$, which means that we can assume a constant beam size for the pump and the signal in the crystal (having a length of $2.5 \mathrm{~mm}$ ). As the $\mathrm{Yb}$ : KYW crystal introduces relatively low losses and is pumped on the both sides in the $914 \mathrm{~nm}$ linear cavity, we can assume that the intracavity power $P_{914}$ is constant in each point of the crystal. For the calculations, we used the rate equations and the gain coefficient given in [19]. We assume that the effective emission cross section at $914 \mathrm{~nm}$ is null for $\mathrm{Yb}: \mathrm{KYW}$ and that the transverse profile of the laser beam at $914 \mathrm{~nm}$ has a Gaussian shape. For a very small laser signal (meaning that the laser intensity can be neglected in the calculation), we can write the small signal gain coefficient at the wavelength $\lambda(981,1000$, or $1023 \mathrm{~nm}$ ) as

$$
g_{0}\left(r, \lambda, P_{914}\right)=n_{t} \frac{\sigma_{\mathrm{el}}(\lambda) \cdot \sigma_{\mathrm{ap}} \frac{2 P_{914}}{h \nu_{914} \pi w_{914}^{2}} \exp \left(-\frac{2 r^{2}}{w_{914}^{2}}\right)-\frac{\sigma_{\mathrm{al}}(\lambda)}{\tau}}{\sigma_{\mathrm{ap}} \frac{2 P_{914}}{h \nu_{914} \pi w_{914}^{2}} \exp \left(-\frac{2 r^{2}}{w_{914}^{2}}\right)+\frac{1}{\tau}},
$$

where $\nu_{914}$ is the frequency associated to the wavelength $914 \mathrm{~nm}$ and $w_{914}=40 \mu \mathrm{m}$ is the $914 \mathrm{~nm}$ beam size.

Assuming that the beam size is also constant at the wavelength $\lambda$, with a radius denoted $w_{\lambda}$, the small signal gain $G_{0}$ can be expressed as a function of the intracavity power at $914 \mathrm{~nm}$ and the wavelength $\lambda$ :

$$
G_{0}\left(\lambda, P_{914}\right)=\operatorname{Exp}\left(l \cdot \int_{0}^{r} \frac{4 g_{0}\left(r, \lambda, P_{914}\right)}{w_{\lambda}^{2}} \cdot \exp \left(-\frac{2 r^{2}}{w_{\lambda}^{2}}\right) r \mathrm{~d} r\right)
$$

where $l$ is the length of the $\mathrm{Yb}: \mathrm{KYW}$ and $r_{c}$ is the crystal radius (1.5 mm in our case).

Figure 5 shows the small signal gain versus the intracavity pump power at $914 \mathrm{~nm}$. The shapes are very different versus the wavelength. The gain starts to be very close to 0 at $981 \mathrm{~nm}$ (strong signal absorption) and becomes high for large intracavity pump powers. This behavior can be related to the three-level nature of this transition coupled with a strong effective emission cross section. Conversely, the lower levels of the transitions at 1000 and $1023 \mathrm{~nm}$ are less thermally populated, involving higher gain at low pump power, but the smaller effective emission cross section at these wavelengths limits the gain value at high pump power levels.

The oscillation threshold is also related to the cavity losses. As the transmission of the cavity mirrors varies as a function of the wavelength, we introduce $T(\lambda)$, the transmission of the "cold" cavity (i.e., without the gain media) after one round trip. This quantity results from the knowledge of the transmission curves of the cavity mirrors and the passive losses (denoted as $L$ and should be independent of the wavelength). Consequently,

$$
T(\lambda)=T_{1}(\lambda)+T_{2}(\lambda)+T_{3}(\lambda)+T_{4}(\lambda)+L,
$$

where $T_{1}, T_{2}, T_{3}$, and $T_{4}$ are the transmissions of the mirrors $M_{1}, M_{2}, M_{3}$, and $M_{4}$, respectively.

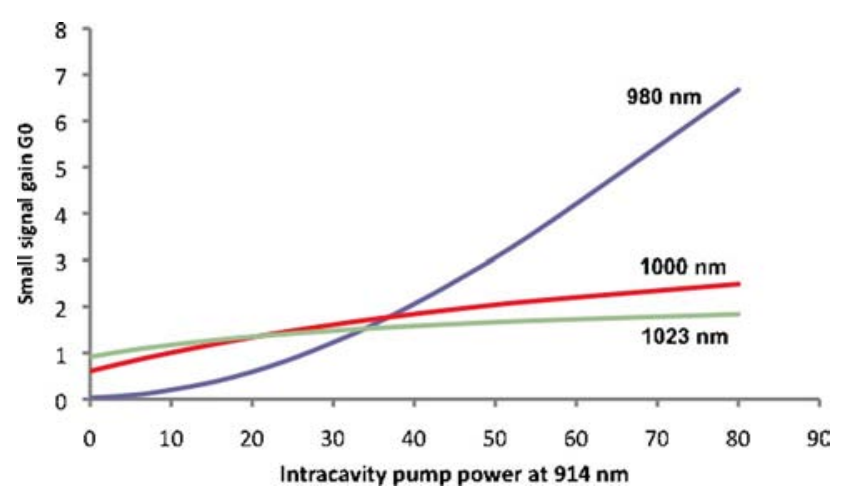

Fig. 5. (Color online) Small signal gain calculated at 981, 1000, and $1023 \mathrm{~nm}$ as a function of the intracavity pump power at $914 \mathrm{~nm}$. For the three wavelengths, the beam size $w_{\lambda}$ is equal to $50 \mu \mathrm{m}$.

Moreover, at a fixed intracavity power $P_{914}$, we introduce the threshold cavity transmission $T_{\text {th }}\left(\lambda, P_{914}\right)$ corresponding to the value of the cavity transmission needed to reach the oscillation threshold at the considered wavelength. Following this definition, $T_{\text {th }}$ is related to the small signal gain by

$$
T_{\text {th }}\left(\lambda, P_{914}\right)=1-\frac{1}{G_{0}^{2}\left(\lambda, P_{914}\right)} .
$$

The benefit to using this quantity is that the discussion can be concentrated on the transmission of the mirrors. As it is shown in the end of this section, the use of $T_{\text {th }}$ enables one to deduce the mirror transmission values needed for laser oscillation at $981 \mathrm{~nm}$ very easily.

Figure $\underline{6}$ presents the threshold cavity transmission $T_{\text {th }}$ at the three wavelengths of interest (981, 1000, and $1023 \mathrm{~nm}$ ) for different intracavity powers at $914 \mathrm{~nm}$. For better legibility, lines between points have been plotted. A value of zero for $T_{\text {th }}$ means that the laser must operate without losses to reach the oscillation threshold: this value is obtained when the pump power is equal to the pump transparency (i.e., $G_{0}$ is equal to unity). Conversely, a negative value for $T_{\text {th }}$ would correspond an absorbant laser medium, where the population inversion is not high enough to reach the transparency (i.e., $G_{0}$ is less than unity). A negative value has no physical significance (and is not represented on the Fig. 6); it just indicates that the oscillation threshold cannot be reached.

For low powers at $914 \mathrm{~nm}(8 \mathrm{~W})$, the oscillation threshold can be reached only at $1023 \mathrm{~nm}$ as this transition requires only a small amount of population inversion to reach the transparency. The lower level of the laser transition being more populated at $1000 \mathrm{~nm}$, the pump power required to reach the transparency is higher (typically between 8 and $16 \mathrm{~W}$ ). This effect is even more pronounced at $981 \mathrm{~nm}$ since a pump power between 24 and $32 \mathrm{~W}$ is needed. Thanks to Fig. $\underline{6}$, we can also observe the evolution of the cavity threshold transmission when the pump power increases for the three wavelengths. It is clear that $T_{\text {th }}$ increases at a much smaller rate at 1023 than at 1000 than at $981 \mathrm{~nm}$. This is due to the effective emission cross section increasing from 1023 to $981 \mathrm{~nm}$ : once the transparency is reached, the gain in the medium is very high at $981 \mathrm{~nm}$ (as shown in Fig. 5). As an example, $T_{\text {th }}$ can reach a value of $97.7 \%$ at $981 \mathrm{~nm}$ for an intracavity pump power of $80 \mathrm{~W}$. This corresponds to a large small signal gain of $G_{0}=6.6$. Consequently, the shape of $T_{\text {th }}$ versus the wavelength is modified following the intracavity pump power. At low intracavity power, it has a maximum at $1023 \mathrm{~nm}$. Next, it peaks at 


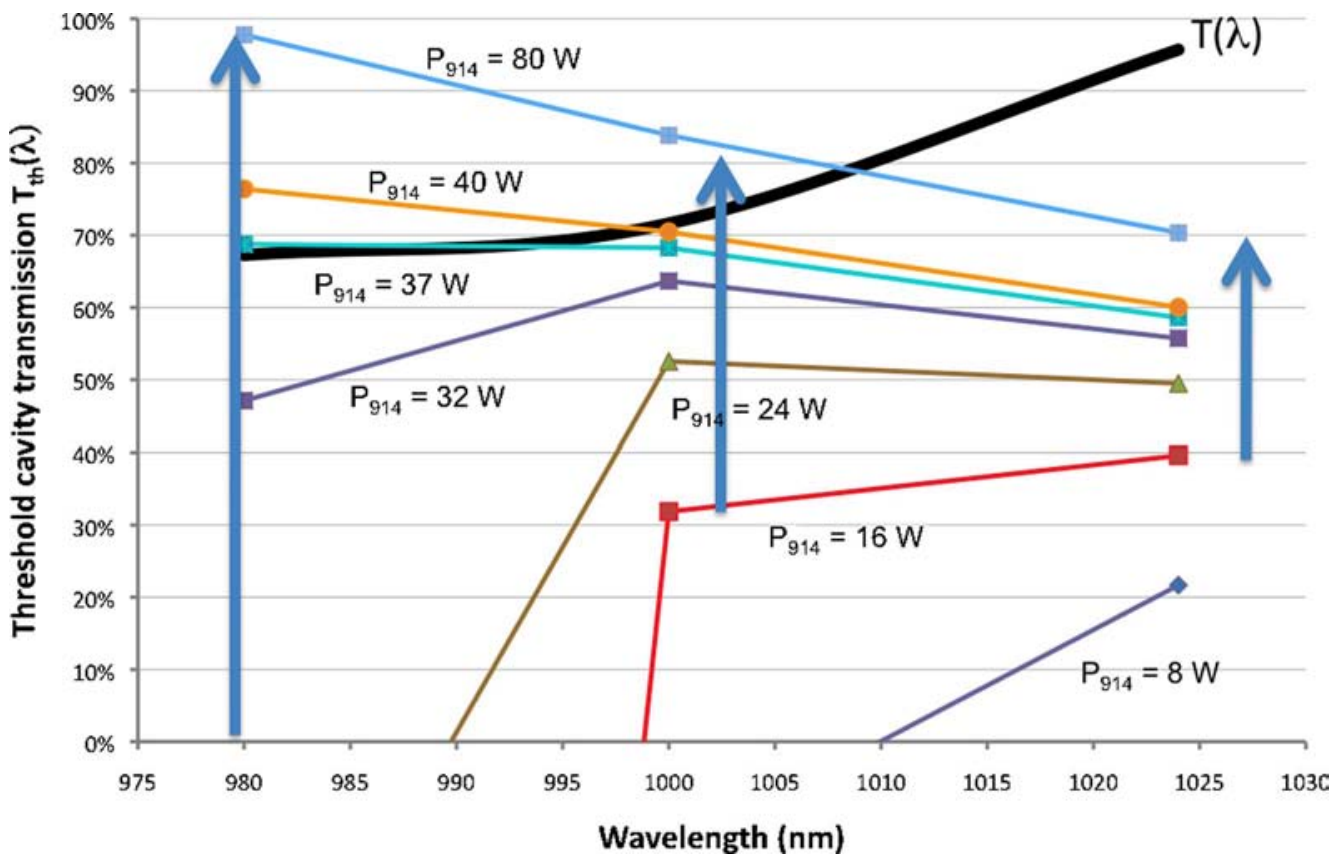

Fig. 6. (Color online) Threshold cavity transmission $T_{\text {th }}$ at the three wavelengths of interest (981, 1000, and 1023 nm) for different intracavity powers at $914 \mathrm{~nm}$. The arrows show the moving of $T_{\text {th }}$ when the intracavity power increases.

$1000 \mathrm{~nm}$ for intracavity power between 16 and $32 \mathrm{~W}$. Finally, it has a maximum at $981 \mathrm{~nm}$ for higher values of $P_{914}$.

In order to know which wavelength can reach the threshold first, one has to consider the cavity transmission curve $T(\lambda)$, as defined earlier. One example is given in Fig. 6 for a set of mirrors having a lower transmission at $981 \mathrm{~nm}$ (the passive losses are estimated to be 1\%). At a given pump power, the oscillation threshold is reached if $T_{\text {th }}\left(\lambda, P_{914}\right)=T(\lambda)$. As an example, Fig. 6 shows that the oscillation threshold is reached close to $37 \mathrm{~W}$ for the $981 \mathrm{~nm}$ wavelength and at higher powers at 1000 and $1023 \mathrm{~nm}$.

To understand the line competition, one has to know which wavelength reaches the oscillation threshold first. We assume that the intracavity pump power varies continuously from zero to its maximum value when the laser is switched on. Given the shapes of $T_{\mathrm{th}}\left(\lambda, P_{914}\right)$ and the way $T_{\mathrm{th}}\left(\lambda, P_{914}\right)$ increases when $P_{914}$ increases, it is clear that the first wavelength to reach the oscillation threshold is $981 \mathrm{~nm}$ in the particular case of $T(\lambda)$ presented in Fig. 6 . Once the oscillation threshold is reached, the gain is clamped at its value at threshold. This means that $T_{\text {th }}\left(\lambda, P_{914}\right)$ does not move once the laser is running, as this quantity is related to the gain by Eq. (5). Consequently, the oscillation threshold can never be reached at 1000 and $1023 \mathrm{~nm}$. In this case, we observed a laser oscillation at $981 \mathrm{~nm}$ only. This behavior was experimentally confirmed. Figure 7 presents the output power at $981 \mathrm{~nm}$ versus the pump power of the $\mathrm{Nd}: \mathrm{YVO}_{4}$ laser. An output power of $1 \mathrm{~W}$ has been achieved in this configuration.

We also tested other output couplers $\left(M_{4}\right)$ having lower transmissions and other spectral shapes. Figure $\underline{8}$ gives the transmission cavity curve in two cases $\left[T_{1}(\lambda)\right.$ and $\left.T_{2}(\lambda)\right]$. Even if $T_{\mathrm{th}}\left(\lambda, P_{914}\right)$ is given for fixed values of $P_{914}$ in Fig. 8 (for the sake of simplicity), we can estimate the oscillation threshold and deduce the wavelength that reaches the threshold first. The method is to consider the slope of $T_{\text {th }}\left(\lambda, P_{914}\right)$ with respect to the slope of the transmission cavity curves. Let us study the curve $T_{\text {th }}(\lambda, 32 \mathrm{~W})$ with respect to $T_{1}(\lambda)$ as an exam- ple: the wavelengths 981 and $1000 \mathrm{~nm}$ seem to be above the oscillation threshold. However, one has to consider which wavelength reaches the threshold first. As the slope of $T_{\text {th }}(\lambda, 32 \mathrm{~W})$ between 981 and $1000 \mathrm{~nm}$ is larger than the slope of $T_{1}(\lambda)$, it is also the case for the slope of $T_{\mathrm{th}}\left(\lambda, P_{914}\right)$ for lower values of pump power [see the evolution of $T_{\text {th }}\left(\lambda, P_{914}\right)$ in Fig. 8]. Consequently, when the laser reaches the threshold at $1000 \mathrm{~nm}$ (for a pump power of approximately $30 \mathrm{~W}$ ), the laser is below the threshold at $981 \mathrm{~nm}$. Finally, the laser oscillates only at $1000 \mathrm{~nm}$ for the transmission cavity $T_{1}(\lambda)$.

The same demonstration can be carried out for the transmission cavity $T_{2}(\lambda)$ : in this case, the first wavelength appearing is $1023 \mathrm{~nm}$ at a pump power of approximately $10 \mathrm{~W}$. Both cases were experimentally confirmed [9].

Hence, the choice of the mirror transmission is critical in order to operate the laser at $981 \mathrm{~nm}$. Two rules can be set following this study: first, a high output coupling promotes the laser oscillation at $981 \mathrm{~nm}$. For a flat transmission curve $T(\lambda)$, this will correspond to a value of approximately $T(\lambda)=70 \%$ (see Fig. 9). Second, $981 \mathrm{~nm}$ can be favored if we can control the shape of the transmission curve. For a laser oscillation at $981 \mathrm{~nm}$ in a highly reflective cavity at $981 \mathrm{~nm}$ (necessary for SHG), the cavity transmission needs to be higher than $65 \%$ at $1000 \mathrm{~nm}$ and higher than $55 \%$ at $1023 \mathrm{~nm}$ (Fig. 9). It is worth noting that these transmissions are lower than the maximum

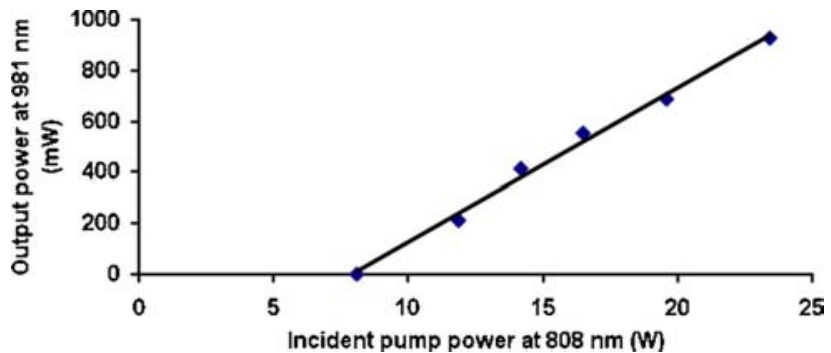

Fig. 7. (Color online) Laser emission at $981 \mathrm{~nm}$ as a function of the pump power for the $\mathrm{Nd}: \mathrm{YVO}_{4}$ laser (at $808 \mathrm{~nm}$ ). 


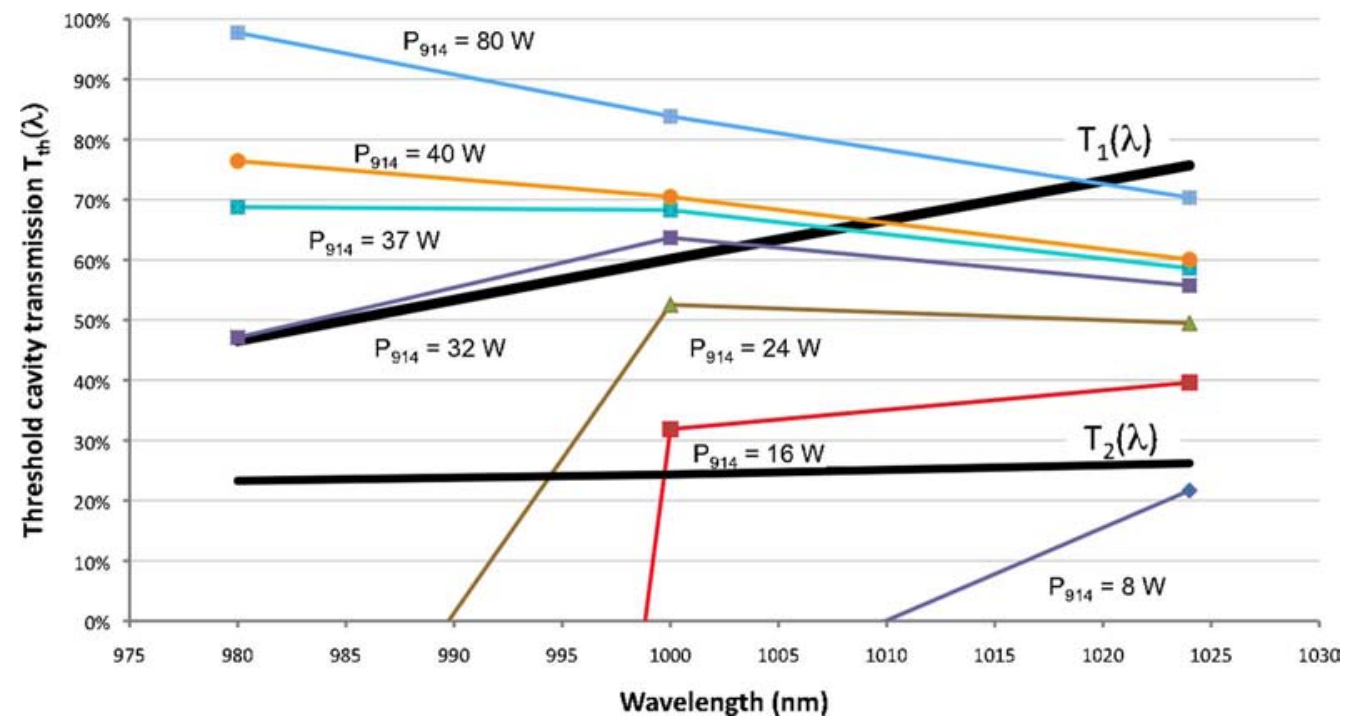

Fig. 8. (Color online) Threshold cavity transmission $T_{\text {th }}$ and cavity transmission in two cases ( $T_{1}$ and $\left.T_{2}\right)$ corresponding to different mirrors $M_{4}$.

values of $T_{\text {th }}$ at the considered wavelengths. A rough analysis would lead one to choose dichroïc mirrors introducing losses at 1000 and $1023 \mathrm{~nm}$ that are higher than the maximum gain. This means $T>T_{\text {th }}$ and corresponds to a transmission higher than $85 \%$ at $1000 \mathrm{~nm}$ and higher than $70 \%$ at $1023 \mathrm{~nm}$. Hence, this analysis of the line competition allows one to reduce the transmission requirements on the cavity mirrors.

\section{EFFECT OF THE TEMPERATURE ON THE LINE COMPETITION}

As mentioned in [9], when we used an output coupler leading to the transmission curve $T_{1}(\lambda)$ (described in Fig. 8 ), we observed a laser oscillation at $1000 \mathrm{~nm}$ at room temperature. However, we observed a wavelength switch at $981 \mathrm{~nm}$ when the temperature reached $360 \mathrm{~K}$ and a laser operation at $981 \mathrm{~nm}$ for higher temperatures. The purpose of this section is to explain how these two transitions are temperature dependent and how they affect the line competition.

The effective absorption cross section is related to the temperature $T$ by the fractional population of the different sublevels:

$$
\sigma_{\mathrm{al}}(T)=\sigma_{\mathrm{al}}\left(T_{0}\right) \frac{f_{a}(T)}{f_{a}\left(T_{0}\right)}
$$

with the fractional population

$$
f_{a}(T)=\frac{\exp \left(-\frac{E_{l}}{k T}\right)}{\sum_{i} \exp \left(-\frac{E_{i}}{k T}\right)},
$$

where $E_{1}$ is the energy level concerned by the transition, $E_{i}$ represents any energy level of the ground state manifold (see Fig. 1), $k$ is the Boltzmann constant, and $T_{0}$ is the reference temperature ( $300 \mathrm{~K}$ in our case).

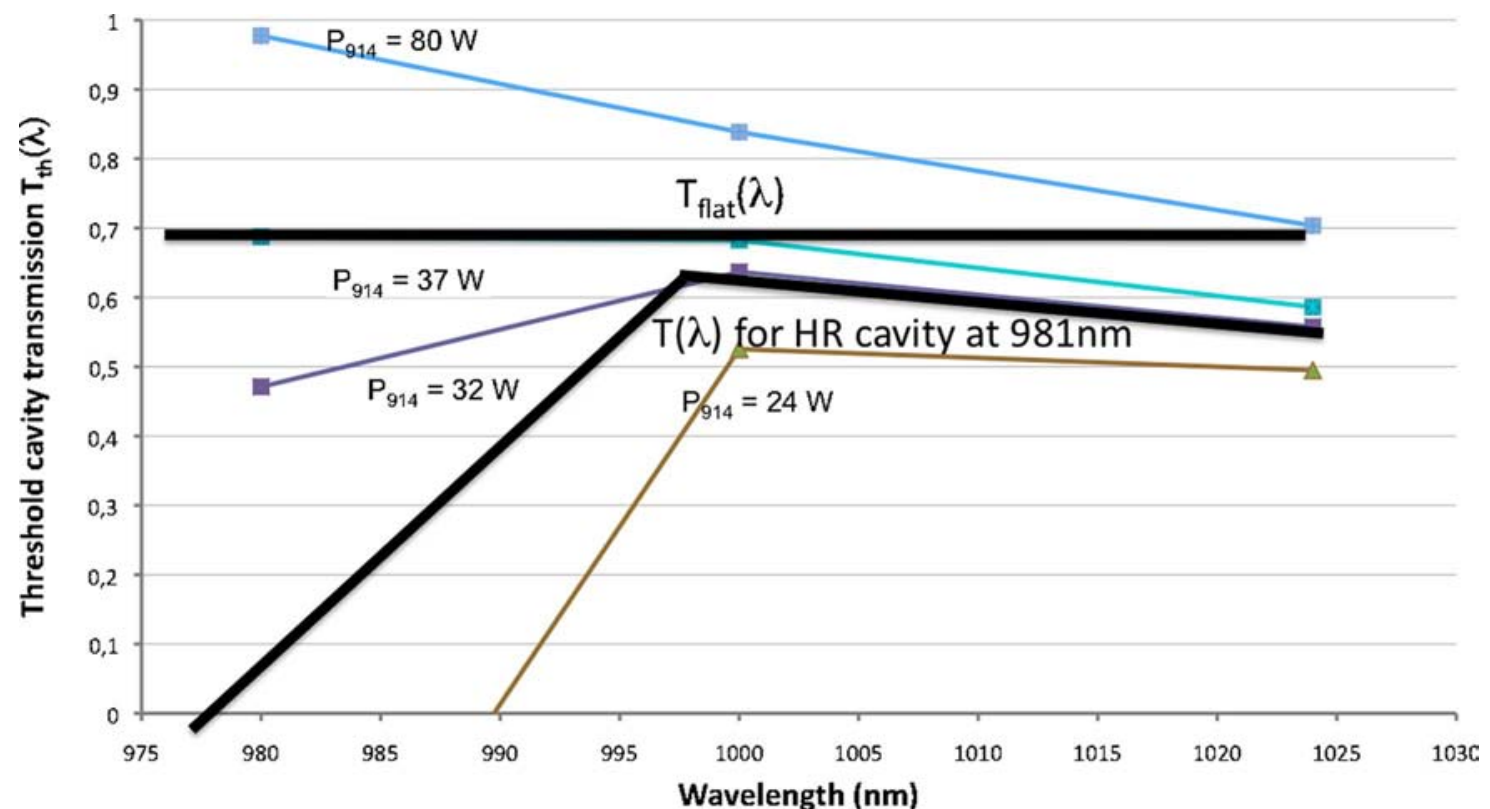

Fig. 9. (Color online) Shape of cavity transmission for laser action at $981 \mathrm{~nm}$ in two cases. Case 1 has a high output coupling and a flat transmission curve $\left(T_{\text {flat }}(\lambda)\right)$. Case 2 has a highly reflective cavity $(T(\lambda)$ for HR cavity at $981 \mathrm{~nm})$. 
In the same way, the effective emission cross section can be expressed versus the temperature:

$$
\sigma_{\mathrm{el}}(T)=\sigma_{\mathrm{el}}\left(T_{0}\right) \frac{f_{e}(T)}{f_{e}\left(T_{0}\right)}
$$

with the fractional population

$$
f_{e}(T)=\frac{\exp \left(-\frac{E_{2}}{k T}\right)}{\sum_{j} \exp \left(-\frac{E_{j}}{k T}\right)},
$$

where $E_{2}$ is the emitting level and $E_{j}$ represents any energy level of the excited state manifold.

Using the Eqs. (6)-(9), we plot the relative variation of the cross sections versus the temperature in Fig. 10. At $981 \mathrm{~nm}$, both emission and effective absorption cross sections decrease versus temperature. This is due to the depletion of the ground state and the emitting level by the Boltzmann law. The effective emission cross section at $1000 \mathrm{~nm}$ follows the same behavior, as it is related to the same emitting level. Conversely, the effective absorption cross section at $1000 \mathrm{~nm}$ increases versus temperature. This is due to the thermal population of the lower level. Figure 10 clearly highlights the difference between a pure three-level transition (981 nm) and the quasi-three-level transition $(1000 \mathrm{~nm})$.

Equations (2) and (3) can be rewritten with a dependency of temperature, including the expressions of $\sigma_{\mathrm{el}}$ and $\sigma_{\mathrm{al}}$ versus temperature. In Eq. (2), two other parameters can vary with the temperature: the effective absorption cross section $\sigma_{\text {ap }}$ and, consequently, the intracavity power at $914 \mathrm{~nm}$ : $P_{914}$. Following the absorption value of our $\mathrm{Yb}: \mathrm{KYW}$ and by the help of Fig. ${ }_{4}$, it is clear that $P_{914}$ increases if the absorption decreases. Consequently, the product $\sigma_{\mathrm{ap}} P_{914}$ [as is stated in Eq. (2)] will be much less sensitive to temperature than the cross sections. It is supposed to be constant to simplify the following calculations.

With the knowledge of the cross sections variation versus temperature, it is possible to calculate the threshold cavity transmission as a function of temperature. This was reported in Fig. 11 for an intracavity pump power of $32 \mathrm{~W}$ at $914 \mathrm{~nm}$

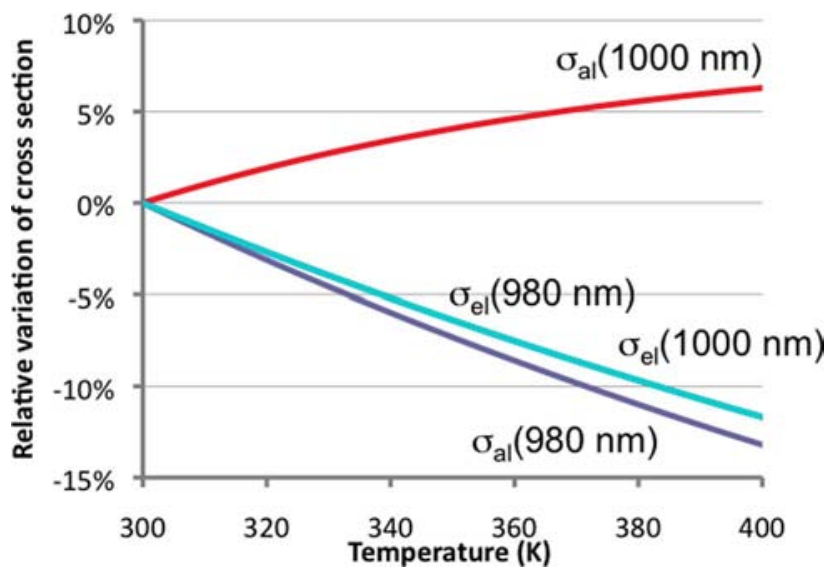

Fig. 10. (Color online) Relative variation of cross sections at 981 and $1000 \mathrm{~nm}$ versus the temperature. The references are the cross sections at $300 \mathrm{~K}$. The curves for the effective emission cross sections are superimposed.

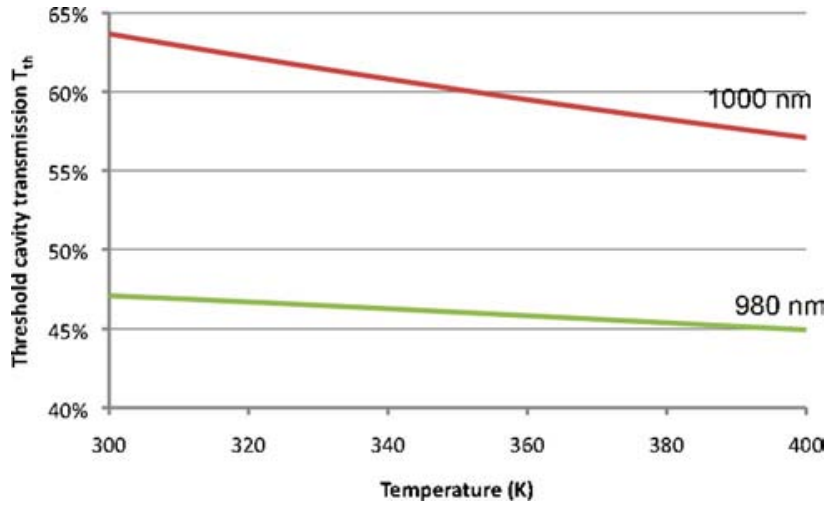

Fig. 11. (Color online) Threshold cavity transmission versus temperature at 981 and $1000 \mathrm{~nm}$ for an intracavity pump power of $32 \mathrm{~W}$ at $914 \mathrm{~nm}$

(close to the oscillation threshold for the cavity transmission $T_{1}$ ). In both cases (981 and $1000 \mathrm{~nm}$ ), the threshold cavity transmission decreases with the temperature. This is of course related to the gain decrease with the temperature, and means that the pump power needs to be higher in order to reach the oscillation threshold. Because of the quasi-three-level nature of the transition at $1000 \mathrm{~nm}$, the decrease of $T_{\text {th }}$ is more pronounced at 1000 than at $981 \mathrm{~nm}$.

Finally, we can use the same approach as the one presented in the previous sections to understand the line competition versus temperature. Figure 12 gives the threshold transmission $T_{\text {th }}$ for three temperatures (300, 360, and $400 \mathrm{~K}$ ) and its position with respect to the cavity transmission $T_{1}(\lambda)$. At $300 \mathrm{~K}$, the first wavelength reaching the oscillation threshold (when the pump power increases) is $1000 \mathrm{~nm}$ for a pump power slightly lower than $32 \mathrm{~W}$, as explained in Section $\underline{4}$. At $360 \mathrm{~K}$, the slope of $T_{\text {th }}$ is exactly the same as the slope of $T_{1}(\lambda)$, which means that both wavelengths reach the oscillation threshold for the same pump power (32 W). At $T=400 \mathrm{~K}$, the slope of $T_{\text {th }}$ is lower than the slope of $T_{1}(\lambda)$. Hence, the oscillation threshold will be reached at $981 \mathrm{~nm}$ first for a pump power slightly higher than $32 \mathrm{~W}$. Consequently, this theoretical analysis is in agreement with the experimental behavior of the laser: at a temperature higher than $360 \mathrm{~K}$, the three-level transition at $981 \mathrm{~nm}$ is promoted.

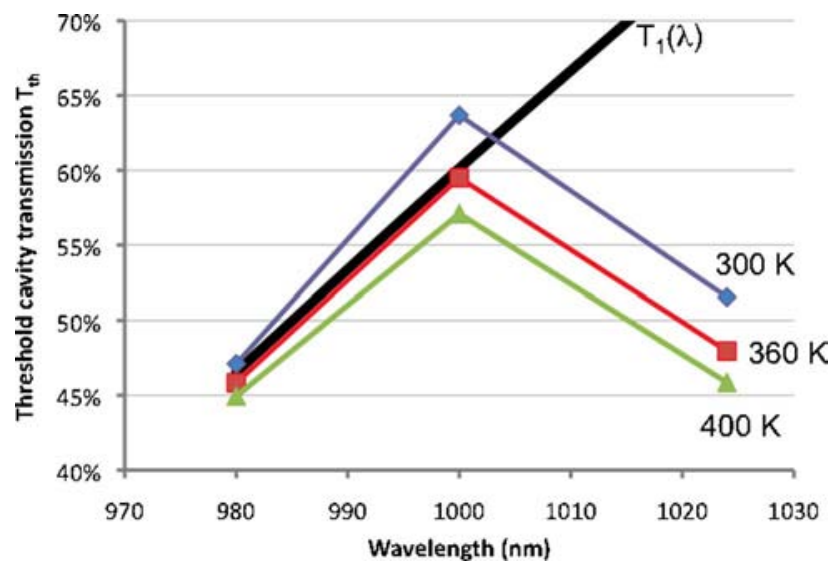

Fig. 12. (Color online) Threshold cavity transmission $T_{\text {th }}$ and cavity transmission $\left(T_{1}\right)$ for three temperatures: 300,360 , and $400 \mathrm{~K}$ for an intracavity pump power of $32 \mathrm{~W}$ at $914 \mathrm{~nm}$. 


\section{CONCLUSION}

This paper has presented a theoretical analysis of an intracavitypumped Yb-doped KYW operating at $981 \mathrm{~nm}$. It gives some guidelines to develop a bulk laser on this three-level transition. It demonstrates that $\mathrm{Yb}$ :KYW is more suitable than $\mathrm{Yb}: \mathrm{KGW}$ because of a less pronounced line competition with the closest quasi-three-level line at $1000 \mathrm{~nm}$.

Then it explained that the crystal absorption needs to correspond to the optimum output coupling for the pump laser in an intracavity pumping configuration. In our case (pumping at $914 \mathrm{~nm}$ with a $\mathrm{Nd}: \mathrm{YVO}_{4}$ laser, itself pumped at $808 \mathrm{~nm}$ ), it corresponds to a double pass absorption of $7 \%$. This order of magnitude can be easily found in standard commercial $\mathrm{Yb}$ :KYW (Ng cut $2.5 \mathrm{~mm}$ long 2\% doped Yb:KYW). In Section 4 , we introduced a simple and original method to explain the line competition occurring in $\mathrm{Yb}: \mathrm{KYW}$ between $981 \mathrm{~nm}$ and the quasi-three-level lines at 1000 and $1023 \mathrm{~nm}$. This method is based on the threshold cavity transmission, a quantity related to the small signal gain of the Yb:KYW. This method enables one to explain the laser behavior experimentally observed: the emission wavelength dependence following the output mirror transmission and its spectral shape. It highlights two ways to promote the $981 \mathrm{~nm}$ transition. First, an output coupler with a large transmission at $981 \mathrm{~nm}$ will favor the $981 \mathrm{~nm}$ emission since the gain on this transition is much higher than the gain at 1000 and $1023 \mathrm{~nm}$. Under these conditions (output coupler with a transmission of 67\%), we achieved an output power of $1 \mathrm{~W}$ at $981 \mathrm{~nm}$ for a pump power at $808 \mathrm{~nm}$ of $22 \mathrm{~W}$. Second, the laser oscillation at $981 \mathrm{~nm}$ only can be achieved thanks to the spectral selectivity of the cavity mirrors, which allows one to operate in a highly reflective cavity at $981 \mathrm{~nm}$ in order to realize intracavity SHG at $490.5 \mathrm{~nm}$. Our analysis of the line competition shows that the transmission requirements at 1000 and $1023 \mathrm{~nm}$ can be relaxed compared to a rough analysis setting that the cavity losses should be higher than the maximum gain at this wavelength. Hence, the cavity transmission should be $65 \%$ at $1000 \mathrm{~nm}$ instead of $85 \%$ and $50 \%$ at $1023 \mathrm{~nm}$ instead of $70 \%$.

Finally, we propose for the first time an analysis of the line competition versus the temperature. The thermal population of the different energy levels, associated with the different nature of the transitions, explain why the three-level line at $981 \mathrm{~nm}$ is favored when the temperature increases. Our analysis is in agreement with the wavelength switch between 1000 and $981 \mathrm{~nm}$ experimentally observed when the temperature reached $360 \mathrm{~K}$.

The results and analysis obtained here can contribute to the design of a microchip laser integrating the intracavity pumping, the highly reflective cavity at $981 \mathrm{~nm}$, and the nonlinear crystal for SHG at $490.5 \mathrm{~nm}$. From a more general point of view, the simplicity of the threshold cavity transmission method to understand the line competition could be useful for other lasers, such as $\mathrm{Nd}$ lasers operating on the three-level transition at $880 \mathrm{~nm}[\underline{20}]$.

\section{REFERENCES}

1. O. G. Okhotnikov, L. A. Gomes, N. Xiang, T. Jouhti, A. K. Chin, R. Singh, and A. B. Grudinin, "981 nm picosecond fiber laser," IEEE Photon. Technol. Lett. 15, 1519-1521 (2003).

2. K. H. Ylä-Jarkko, R. Selvas, D. B. S. Soh, J. K. Sahu, C. A. Codemard, J. Nilsson, S. A. Alam, and A. B. Grudinin, "A
$3.5 \mathrm{~W} 977 \mathrm{~nm}$ cladding pumped jacketed air clad ytterbium doped fiber laser," in Advanced Solid-State Photonics, J. Zayhowski, ed., Vol. 83 of OSA Trends Optics Photonics (Optical Society of America, 2003), paper 103.

3. J. Boullet, Y. Zaouter, R. Desmarchelier, M. Cazaux, F. Salin, J. Saby, R. Bello-Doua, and E. Cormier, "High power ytterbiumdoped rod-type three- level photonic crystal fiber laser," Opt. Express 16, 17891-17902 (2008).

4. F. Röser, C. Jauregui, J. Limpert, and A. Tünnermann, "94 W $981 \mathrm{~nm}$ high brightness Yb-doped fiber laser," Opt. Express 16, 17310-17318 (2008).

5. D. B. S. Soh, C. Codemard, S. Wang, J. Nilsson, J. K. Sahu, F. Laurell, V. Philippov, Y. Jeong, C. Alegria, and S. Baek, "A $981 \mathrm{~nm}$ Yb-doped fiber MOPA source and its frequency doubling," IEEE Photon. Technol. Lett. 16, 1032-1034 (2004).

6. A. Bouchier, G. Lucas-Leclin, and P. Georges, "Frequency doubling of an efficient continuous wave single-mode $\mathrm{Yb}$-doped fiber laser at $978 \mathrm{~nm}$ in a periodically-poled $\mathrm{MgO}: \mathrm{LiNbO} 3$ waveguide," Opt. Express 13, 6974-6979 (2005).

7. M. Castaing, F. Balembois, P. Georges, T. Georges, K. Schaffers, and J. Tassano, "Diode-pumped Nd:YVO4/Yb:S-FAP laser emitting at 985 and $492.5 \mathrm{~nm}$," Opt. Lett. 33, 1234-1236 (2008).

8. A. Bouchier, G. Lucas-Leclin, F. Balembois, and P. Georges, "Intense laser emission at $981 \mathrm{~nm}$ in an Ytterbium-doped $\mathrm{KY}\left(\mathrm{WO}_{4}\right)_{2}$ crystal," in Advanced Solid-State Photonics (TOPS), C. Denman and I. Sorokina, eds., Vol. 98 of OSA Trends Optics Photonics (Optical Society of America, 2005), paper TuB5.

9. M. Castaing, F. Balembois, P. Georges, and T. Georges, "Diode-pumped $\mathrm{Yb}: \mathrm{KYW}$ laser emitting at $981 \mathrm{~nm}$ by intracavity pumping," Proc. SPIE 7193, 71930J (2009)

10. Y. F. Lü, X. H. Zhang, J. Xia, R. Chen, G. Y. Jin, J. G. Wang, C. L. $\mathrm{Li}$, and Z. Y. Ma, "981 nm Yb:KYW laser intracavity pumped at $912 \mathrm{~nm}$ and frequency-doubling for an emission at $490.5 \mathrm{~nm}$," Laser Phys. Lett. 7, 343-346 (2010).

11. N. V. Kuleshov, A. Alagatsky, A. V. Podlipensky, V. P. Mikhailov, and G. Huber, "Pulsed laser operation of $\mathrm{Yb}$-doped $\mathrm{KY}\left(\mathrm{WO}_{4}\right)_{2}$ and $\mathrm{KGd}\left(\mathrm{WO}_{4}\right)_{2}$," Opt. Lett. 22, 1317-1319 (1997).

12. S. A. Payne, L. D. DeLoach, L. K. Smith, W. L. Kway, J. B. Tassano, W. F. Krupke, B. H. T. Chai, and G. Loutts, "Ytterbium-doped apatite-structure crystals: a new class of laser materials," J. Appl. Phys. 76, 497-503 (1994).

13. A. A. Lagatsky, N. V. Kuleshov, and V. P. Mikhailov, "Diodepumped $\mathrm{CW}$ lasing of $\mathrm{Yb}: \mathrm{KYW}$ and $\mathrm{Yb}: \mathrm{KGW}$," Opt. Commun 165, 71-75 (1999).

14. Eksma Optics, "Yb:KGW and Yb:KYW crystals," http://www. eksmaoptics.com/en/p/yb-kgw-and-yb-kyw-crystals-498? $\mathrm{t}=$ brochures.

15. S. Bjurshagen, J. E. Hellström, V. Pasiskevicius, M. Cinta Pujol, M. Aguiló, and F. Díaz, "Fluorescence dynamics and rate equation analysis in Er3+ and $\mathrm{Yb} 3+$ doped double tungstates," Appl. Opt. 45, 4715-4725 (2006).

16. A. A. Demidovich, A. N. Kuzmin, G. I. Ryabtsev, M. B. Danailov, W. Strek, and A. N. Titov, "Influence of $\mathrm{Yb}$ concentration on Yb:KYW laser properties," J. Alloys Compd. 300-301, 238-241 (2000).

17. N. V. Kuleshov, A. A. Lagatsky, A. V. Podlipensky, V. P. Mikhailov, E. Heumann, A. Diening, and G. Huber, "Highly efficient CW and pulsed lasing of $\mathrm{Yb}$ doped tungstates," in Advanced Solid State Lasers, C. Pollock and W. Bosenberg, eds., Vol. 10 of OSA Trends in Optics and Photonics Series (Optical Society of America, 1997), paper SC3.

18. S. So, J. I. Mackenzie, D. P. Shepherd, W. A. Clarkson, J. G. Betterton, E. K. Gorton, and J. A. C. Terry, "Intra-cavity side-pumped Ho:YAG laser," Opt. Express 14, 10481-10487 (2006)

19. F. Augé, F. Druon, F. Balembois, P. Georges, A. Brun, F. Mougel G. Aka, and D. Vivien, "Theoretical and experimental investigations of a diode-pumped quasi-three level laser: the $\mathrm{Yb}^{3+}$-doped $\mathrm{Ca}_{4} \mathrm{GdO}\left(\mathrm{BO}_{3}\right)_{3}(\mathrm{Yb}$ :GdCOB$)$ laser," IEEE J. Quantum Electron. 36, 598-606 (2000).

20. M. Castaing, E. Hérault, F. Balembois, P. Georges, C. Varona, P. Loiseau, and G. Aka, "Diode-pumped Nd:YAG laser emitting at $899 \mathrm{~nm}$ and below," Opt. Lett. 32, 799-801 (2007). 